\title{
OS PARADOXOS DA ACUMULAÇÃO FLEXÍVEL E SEUS REFLEXOS NA EXPLORAÇÃO DAS MULHERES DA CLASSE TRABALHADORA EM SANTA CATARINA/BRASIL
}

\author{
Debora Aparecida Almeida \\ Universidade do Contestado (UnC)
}

OS PARADOXOS DA ACUMULAÇÃO FLEXÍVEL E SEUS REFLEXOS NA EXPLORAÇÃO DAS MULHERES DA CLASSE TRABALHADORA EM SANTA CATARINA/BRASIL

Resumo: O presente texto aborda questões relativas à exploração de mulheres trabalhadoras no Estado de Santa Catarina (Brasil) em período recente. A reflexão tem por base método de pesquisa permeado de estudo reflexivo e dialético e levantamentos bibliográficos e documentais. No desenvolvimento da argumentação, contextualiza questões concernentes às mudanças no mercado de trabalho relacionadas ao processo de acumulação flexível, destacadamente a exploração da mão-de-obra feminina, apreendida como ponto crucial para a análise de avanços e retrocessos do papel da mulher sob o enfoque capitalista. Conclui que a exploração desenfreada do capital tende a aumentar a desigualdade de gênero, na verdade, torna-a ainda mais perigosa.

Palavras-chave: Acumulação flexível, exploração, mulheres.

THE PARADOXES OF FLEXIBLE ACCUMULATION AND ITS CONSEQUENCES IN THE EXPLORATION OF THE WORKING CLASS WOMEN IN SANTA CATARINA/BRAZIL

Abstract: The present text approaches questions related to working women's exploitation in the state of Santa Catarina - Brazil in the recent periods. The reflection is based permeated research method of reflective and dialectical study and bibliographic and documentary surveys. In developing the argument contextualizes questions concerning the changes in the labor market related to the flexible accumulation process, notably the exploitation of labor, women workers, perceived as a crucial point for the analysis of advances and setbacks of the role of women in the focus capitalist It. Lastly, it's concluded that the unbridled exploitation of the capital tends to widen the gender inequality, truly making it even more dangerous

Key words: Flexible accumulation, exploitation, women. 


\section{INTRODUÇÃO}

Considerando a evolução do sistema capitalista e seus reflexos no mercado de trabalho brasileiro percebe-se que a economia catarinense foi sendo estruturada paulatinamente por um sistema de acumulação flexível em consonância com o capitalismo de outros estados da federação.

Para Goularti Filho (2003, p. 21, grifo do autor)

\begin{abstract}
Uma das peculiaridades da formação econômica de Santa Catarina é a forte presença do capital de origem local. Talvez o que diferencia Santa Catarina em relação a outras regiões é justamente a palavra forte.
\end{abstract}

O fordismo periférico e a exploração da força de trabalho de forma desordenada contribuem para que o desenvolvimento desigual se mantenha fortalecido. Apesar da forte caracterização econômica do Estado de Santa Catarina ser considerada um exemplo para outros estados, é preciso reconhecer que esse mesmo progresso oriundo do fortalecimento do setor produtivo reflete nitidamente nas desigualdades e discrepâncias no ambiente de trabalho das mais conhecidas organizações de sucesso.

Por trás das belas propagandas e dos produtos de qualidade, escondem-se rostos femininos que são abruptamente explorados pelo sistema capitalista. A ilusão de um espaço conquistado vai perdendo o encanto na medida em que as mulheres ainda são discriminadas e tem relações de trabalho diferenciadas, seja pelo salário, seja pela forma que são tratadas dentro das organizações.

Pretende-se com este estudo analisar como a exploração do trabalho das mulheres tem se refletido diante do processo de acumulação flexível. No decurso do trabalho, propõe-se cumprir com uma crítica pontual e reflexiva sobre a realidade do mercado de trabalho periférico e suas consequências nas relações de trabalho.

\section{PERCALÇOS DO FORDISMO E SUA EVOLUÇÃO PERIFÉRICA: marco introdutório}

Para entender o desenvolvimento é preciso fazer conexões entre o sistema econômico e a organização social e política das sociedades subdesenvolvidas. Asituação de subdesenvolvimento produziu-se historicamente quando a expansão do capitalismo comercial e industrial vinculou ao mercado economias com graduações variadas no sistema produtivo. O fordismo é entendido como ultrapassado para muitos sistemas produtivos, no entanto, percebe-se que ainda não foi totalmente superado por outros sistemas mais modernos.
A sistemática fordista pautada na linha de produção e na massificação continua vigente e desenfreadamente implementada, o discurso modernizador de gestão participativa ainda é incipiente diante das práticas industriais desenvolvidas pelos continentes.

As novas tecnologias trouxeram consigo entre suas variadas potencialidades, mecanismos que asseguram a diferenciação do controle da qualidade total através de posições semelhantes e contraditórias, em alguns sentidos revolucionários e em outro reformista as sistemáticas do taylorismofordismo. A função do Estado mudou radicalmente e de acordo com a tese neoliberal reduziu e minimizou sua intervenção econômica. O fim das políticas igualitárias do Estado do bem-estar social serviu como base no estreitamento do controle do mercado de trabalho. (INVERNIZZI, 2004)

Harvey (2003) considera que as empresas em geral possuem um capital ocioso que poderia ser utilizado para ampliar a competitividade. Vários são os fatores que influenciam essa posição como avanços tecnológicos, facilidade de comunicação, rapidez de acesso às informações, dentre outros.

Onde a produção podia ser padronizada, mostrou-se difícil parar o seu movimento de aproveitar-se da força de trabalho mal remunerada do terceiro mundo, criando ali o que Lipietz (1991) chama de fordismo periférico. Portanto esse processo ampliou-se mundialmente

\begin{abstract}
A questão de mundialização dá origem de muitas dificuldades, em primeira linha as que concernem ao modo de articulação entre o nacional e o internacional, entre o local e o global. Neste ponto, muito esquematicamente, duas linhas fundamentais de interpretação do processo mundial são disponíveis. (BENKO, 2002, p. 43).
\end{abstract}

O trabalho organizado foi solapado pela reconstrução de focos de acumulação flexível em regiões que careciam de tradições industriais anteriores e pela reimportação para os centros mais antigos das normas e práticas regressivas estabelecidas nessas novas áreas (HARVEY, 2003).

Cabe aqui lembrar que

O termo mundialização lembra um pouco os infortúnios semânticos da noção de modernidade: seu conceito varia segundo as estratégias contraditórias de definição que não designam nem os mesmos aspectos nem o mesmo campo de aplicação do fenômeno considerado. (BENKO, 2002, p. 41 , grifo do autor). 


\subsection{As mudanças do mercado de trabalho em período recente}

Guimarães Neto (1997) reforça que embora seja verdade que a queda da importância do poder sindical reduziu o singular poder dos trabalhadores brancos do sexo masculino nos mercados do setor monopolista, não é verdade que os excluídos desses mercados de trabalho - negros, mulheres, minorias étnicas de todo tipo - tenham adquirido uma súbita paridade (exceto no sentido de que muitos operários homens e brancos tradicionalmente privilegiados foram marginalizados, unindo-se aos excluídos). Mesmo que algumas mulheres e algumas minorias tenham tido acesso a posições mais privilegiadas, as novas condições do mercado de trabalho de maneira geral reacentuaram a vulnerabilidade dos grupos desprivilegiados. Em todos esses casos, o efeito é uma transformação. Para Aloísio Ruscheinsky (2004, p. 20)

O ambiente pode ser uma ideologia ou também uma ciência ou uma proposta de defesa de valores. Em todas as circunstancias é desafiado pela violência, pelos conflitos e pelos interesses que perpassam o cotidiano e a organização da sociedade. Essas são qualidades ou defeitos que não desaparecerão mesmo com a implementação do ambientalismo como politica hegemônica na sociedade. A ousadia do ambientalismo consiste em juntar ou ajustar num mesmo cenário a sociedade moderna de consumo e a conservação dos bens naturais no patamar da sustentabilidade do modo de controle do trabalho e de emprego.

Nota-se que uma frequente redução do emprego regular em favor do crescente uso do trabalho em tempo parcial, temporário ou subcontratado. O resultado é uma estrutura de mercado de trabalho do tipo detalhado na retirada. Esses arranjos de emprego flexíveis não criam por si mesmos uma insatisfação trabalhista forte, visto que a flexibilidade pode às vezes ser mutuamente benéfica. Mas os efeitos agregados, quando se consideram a cobertura de seguro, os direitos de pensão, os níveis salariais e a segurança no emprego, de modo algum parecem positivos do ponto de vista da população trabalhadora como um todo (GUIMARÃES NETO, 1997).

O ambiente de trabalho é circundado por relações bem específicas. Se por um lado existem os trabalhadores sindicalizados, por outro existem os clãs familiares que se perpetuam mundo afora vendando os olhos da classe trabalhadora para suas artimanhas de manipulação e exploração de uma mão-de-obra fidelizada.

Os tubarões do capitalismo por assim dizer, se perpetuam de geração para geração e os modernismos de gestão são proliferados por eles em seus discursos motivacionais, no entanto os trabalhadores continuam sua trajetória com a ilusão de que são reconhecidos e valorizados.

Conforme Hannah Arendt (2010, p. 8)

\begin{abstract}
O trabalho é a atividade que corresponde ao processo biológico do corpo humano, cujo crescimento espontâneo, metabolismo e resultante declínio estão ligados às necessidades vitais produzidas e fornecidas ao processo vital pelo trabalho. A condição humana do trabalho é a própria vida. A Obra é a atividade correspondente a não naturalidade da existência humana, que não esta engastada no sempre-recorrente ciclo vital da espécie e cuja mortalidade não é compensada por este último. A obra proporciona um mundo 'artificial' de coisas, nitidamente diferente de qualquer ambiente natural. Dentro de suas sobreviver e a transcender todas elas. A condição humana da obra é a mundanidade.
\end{abstract}

Parece-nos bastante atual que a ideologia do progresso acumulação corroborou substancialmente para as transformações sociais e culturais, as mudanças ocorridas no sistema de dominação social serviram como sustentáculo para o processo acumulativo. O processo civilizatório industrial contribui na alavanca ideológica para fomentar a consciência de solidariedade internacional, e assim, a anulação cumulativa da memória histórica padroniza e limita dados anteriormente importantes. Conforme Benko (2002), precisamos viver esse momento singular de mundialização, mas nem por isso, precisamos deixar de denunciá-lo.

\subsection{Questões pontuais sobre a divisão sexual do trabalho}

Tratar sobre o trabalho da mulher requer definir conceitualmente a divisão sexual do trabalho. Desta forma cabe-nos citar Hirata e Kergoat (2007, p. 599)

A divisão sexual do trabalho é a forma de divisão do trabalho social decorrente das relações sociais entre os sexos; mais do que isso, é um fator prioritário para sobrevivência da relação social entre os sexos. Essa forma é modulada histórico e socialmente. Tem como característica a designação prioritária dos homens à esfera reprodutiva e, propusemos distinguir claramente os princípios da divisão sexual do trabalho e suas modalidades.

É preciso que as mulheres contribuam para o desenvolvimento regional no sentido de entendêlo como

[...] processo localizado de crescimento econômico e mudança social, que tem como objetivo principal a progressiva 
melhoria da qualidade material $e$ espiritual de vida de uma comunidade e de seus respectivos membros que vivem num determinado espaço regional. (THEIS, 2005, p. 4).

Com o advento da precarização e flexibilização do emprego Hirata (2001, p. 8) afirma que

O contexto atual está profundamente marcado por uma transformação dupla e paradoxal - do trabalho, caracterizado, por um lado, pela estabilidade requerida pelos 'novos modelos de produção' que apela ao forte envolvimento do trabalhador, e, de outro, pela insegurança no emprego devida ao desenvolvimento da flexibilidade do trabalho e ao aumento do desemprego. Essa transformação requer uma análise simultânea do conteúdo da atividade e das formas do emprego; da organização do trabalho ao nível da empresa e dos processos de segmentação ao nível do mercado de trabalho. Há complementaridade entre, de um lado, a inovação tecnológica e, de outro, mudanças no status do emprego. Os vínculos de emprego se tornam cada vez mais precários com o aumento do desemprego de longo prazo, de formas ditas 'atípicas' de emprego e da flexibilidade no uso da força de trabalho.

A exploração da força de trabalho feminina se dá pela condição de vítima ou de protagonista, percebe-se que as mulheres podem sim redefinir sua trajetória, basta que façam uso da liberdade que possuem no sentido de empoderarem-se desafiando os estereótipos e contribuindo para transformação da sociedade. Neste sentido ressalta-se que

Na posição de vitimista na há espaço para se resignificarem as relações de poder. Isto revela um conceito rígido de gênero. Em outros termos, a postura vitimista é também essencialista social, uma vez que o gênero é destino. Na concepção flexível aqui exposta não há lugar para qualquer essencialismo, seja biológico ou social. Cabe frisar que a categoria histórica de gênero não constitui uma camisa de força, não prescrevendo, por conseguinte, um destino inexorável. É lógico que o gênero traz em si um destino. Todavia, cada ser humano - homem ou mulher - desfruta de certa liberdade para escolher a trajetória a descrever. (SAFFIOTI, 2001, p. 125)

Em se tratando de um posicionamento de negação da proposição de vitimização, há que se considerar o espaço de territorialidade ocupado pelas mulheres no mercado de trabalho contemporâneo. Para Yannoulas (2013, p. 54)

Analisar a feminização de uma ocupação ou profissão requer constatar quantas de nós estamos em territórios masculinos e femininos, e também refletir sobre quanto tempo dispendemos na realização de afazeres domésticos; isto é: saber o que fazemos, mas também interpretar o porquê de o fazemos, refletir sobre as especificidades desse nosso fazer: • Onde o fazemos - Quando o fazemos . Quanto fazemos • Como aprendemos a fazer • Com quem fazemos $\cdot$ Para quem fazemos.

A divisão de tarefas seja no ambiente profissional, seja no ambiente doméstico pressupões que homens e mulheres estejam dispostos a construir espaços de convivência mais equitativos e produtivos. É perceptível que setores com maior número de homens e áreas mais técnicas existirão enclaves para atuação feminina. Vale mencionar que

Encontramos algumas produções que desvendam os problemas para a inserção de mulheres em territórios altamente masculinizados, que gostaríamos de denominar 'enclaves'. Esta palavra provém do latim inclavatus, significando fechado. Em castelhano se utiliza para fazer referência a um grupo humano inserto em outro de características distintas: por exemplo, enclave curdo na Turquia. Um enclave de mulheres é um território cujas fronteiras geográficas ficam inteiramente dentro dos limites de outro (o de homens). A maioria desses processos de entrada incipiente de mulheres em territórios masculinos está associada à conquista de diplomas de educação superior habilitantes nessas áreas, sob o influxo equalizador do sistema educacional republicano e meritocrático. (YANNOULAS, 2013, p. 54)

A atuação feminina em alguns segmentos da indústria dominados predominantemente por homens reflete claramente a desvalorização do trabalho feminino e demonstra de forma explícita o seu lado mais perverso.

\section{AEXPLORAÇÃO DA MÃO-DE-OBRA FEMININA NO MERCADO DE TRABALHO EM SANTA CATARINA: retrocesso ou avanço?}

Primeiramente cabe esboçar um breve resumo do desenvolvimento econômico do Estado de Santa Catarina para na sequência apresentar uma análise mais pontual dos dados do trabalho da mulher catarinense no mercado de trabalho e seus avanços e retrocessos.

A indústria catarinense ocupa uma posição de destaque no cenário brasileiro, haja vista, que possui segmentos diversificados conferindo as regiões um desenvolvimento equilibrado, dentro desta perspectiva os polos subdividem-se nas seguintes setorizações: 
$\checkmark$ Região Sul: cerâmico, carvão, vesturário e descartáveis plásticos;

$\checkmark$ Região Oeste: alimentar, móveis;

$\checkmark$ Região do Vale do Itajaí: vestuário, naval e cristal;

$\checkmark$ Região Nordeste: metalurgia, máquinas e equipamentos, material elétrico, autopeças, plástico, confecções e mobiliário;

$\checkmark$ Regiao Norte: mobiliário e madeira;

$\checkmark$ Região Serrana: madeira, celulose e papel;

$\checkmark$ Região Sudeste: tecnologia e informática, calçados, pesca e minerais não metálicos.

Conforme informações analisadas pela Federação das Indústrias do Estado de Santa Catarina (FIESC) (2014) o estado ocupa a quarta posição nacional na indústria de transformação e quinta em número de trabalhadores. O Produto Interno Bruto (PIB) catarinense é o sexto do Brasil, vale elucidar que segundo grupo The Economist, Santa Catarina ocupa a quarta posição no ranking nacional em inovação (2013-2014).

Em conformidade com a representatividade e a diversidade industrial do estado de Santa Catarina é possível destacá-lo como o estado que mais gerou empregos em 2014, com a criação de 53.887 novas vagas. O destaque foi o setor de serviços, com a contribuição de 30.217 novas vagas, seguido pelo comércio $(+11.392)$ e a Indústria de Transformação (+5.084). A região sul acompanhou o bom desempenho com saldo positivo de 118.795 novos empregos (BRASIL, 2014).

$\mathrm{Na}$ sequência serão apresentados dados Sistema Nacional de Informações de Gênero (SNIG) do Instituto Brasileiro de Geografia e Estatística (IBGE), o qual reúne dados dos Censos Demográficos de 2000 e 2010. Especificamente neste estudo optou-se pela utilização de dados de 2010 pontuados em informações do Estado de Santa Catarina.

Percebe-se que a representatividade da mulher catarinense na indústria é bem significativa até pela caracterização econômica do estado que apesar da sua dimensão territorial possui um parque industrial bastante diversificado. $\mathrm{Na}$ agricultura o estado possui $2 \%$ acima da média brasileira, na indústria possui $11,6 \%$ acima da média brasileira e na área de serviços encontra-se com 12,6\% abaixo da média brasileira. Sem dúvida a maior expressividade está na área industrial (Tabela 1).

Os homens ainda são maioria no mercado de trabalho de Santa Catarina. São 370 mil a mais. A Pesquisa Nacional por Amostra de Domicílios (PNAD) aponta que Santa Catarina representa hoje o estado com maior diferença salarial entre homens e mulheres (INSTITUTO BRASILEIRO DE GEOGRAFIA E ESTATÍSTICA, 2014)ำ (Tabela 2).
Tabela 1 - Distribuição percentual da população ocupada por setores de atividade (\%)

\begin{tabular}{c|c|c}
\hline Categorias & Brasil & $\begin{array}{c}\text { Santa } \\
\text { Catarina }\end{array}$ \\
\hline Mulheres, 2010 & 31,9 & 29,1 \\
\hline Mulheres, Agricultura, 2010 & 9,9 & 11,9 \\
\hline Mulheres, Indústria, 2010 & 11,8 & 22,4 \\
\hline Mulheres, Serviços, 2010 & 78,3 & 65,7 \\
\hline Fonte: INSTITUTO BRASILEIRO DE GEOGRAFIA E \\
ESTATISTICA. Censo Demográfico 2010. Rio de \\
Janeiro, 2011. Disponível em:<http://www.ibge.gov.br/ \\
home/estatistica/populacao/censo2010/>. Acesso em: \\
31 dez. 2014
\end{tabular}

Tabela 2 - Razão entre o rendimento médio das mulheres ocupadas em relação ao rendimento dos homens ocupados (\%)

\begin{tabular}{c|c}
\hline Divisões Territoriais & $\mathbf{2 0 1 0}$ \\
\hline Brasil & 73,9 \\
\hline Santa Catarina & 67,8
\end{tabular}

Fonte: (INSTITUTO BRASILEIRO DE GEOGRAFIA E ESTATÍSTICA, 2011).

Vale elucidar que apesar de representar um dos cinco Estados brasileiros em que as mulheres estudam mais que os homens, na prática as diferenças a relação formação/remuneração não está fluindo adequadamente. Conforme a PNAD em 2012 o rendimento médio mensal foi de $\mathrm{R} \$ 727,00$ a menos para as mulheres, já em 2013 a diferença aumentou representando $\mathrm{R} \$ 812,00$ a menos para as mulheres (INSTITUTO BRASILEIRO DE GEOGRAFIA E ESTATÍSTICA, 2014).

A mulher como arrimo de família é um fenômeno constante nas estatísticas brasileiras, nota-se que em conformidade com os índices nacionais quanto maior o número de filhos menor a taxa de ocupação. Apesar do Estado de Santa Catarina ter um índice de $4,4 \%$ abaixo da média nacional, ainda demonstra um índice considerável (Tabela 3).

Tabela 3 - Proporção de famílias com mulheres responsáveis pela família (\%)

\begin{tabular}{c|c}
\hline Divisões Territoriais & $\mathbf{2 0 1 0}$ \\
\hline Brasil & 37,3 \\
\hline Santa Catarina & 32,9 \\
\hline
\end{tabular}

Fonte: (INSTITUTO BRASILEIRO DE GEOGRAFIA E ESTATÍSTICA, 2011).

Também é válido mencionar que quanto maior o índice de filhos na creche maior será a taxa de ocupação, mulheres com todos os filhos na creche apresentam cerca de $80 \%$ de ocupaçao.

As mulheres catarinenses assim como as brasileiras contribuem para o rendimento familiar 
aportando recursos para subsidiar o sustento da família, vale mencionar que cada vez mais as mulheres vêm assumindo o sustento da família (Tabela 4).

Tabela 4 - Média do percentual do rendimento das mulheres na família em relação ao rendimento familiar total (\%)

\begin{tabular}{c|c}
\hline Divisões Territoriais & $\mathbf{2 0 1 0}$ \\
\hline Brasil & 40,9 \\
\hline Santa Catarina & 38,4 \\
\hline Fonte: (INSTITUTO BRASILEIRO DE GEOGRAFIA E
\end{tabular}

\section{ESTATÍSTICA, 2011}

Os dados apresentados no Brasil convergem com os índices do Estado, porém, considerando os índices de desenvolvimento econômico a taxa de analfabetismo é bem significativa (Tabela 5).

Tabela 5 - Total de analfabetos (pessoas)

\begin{tabular}{c|c|c}
\hline $\begin{array}{c}\text { Divisões } \\
\text { Territoriais }\end{array}$ & $\mathbf{2 0 1 0}$ & $\begin{array}{c}\text { Mulheres, } \\
\mathbf{2 0 1 0}\end{array}$ \\
\hline Santa Catarina & 197.342 & 107.403 \\
\hline \multicolumn{2}{c}{ Fonte: (INSTITUTO BRASILEIRO DE GEOGRAFIA E } \\
\multicolumn{2}{l}{ ESTATÍSTICA, 2011). }
\end{tabular}

Santa Catarina possui um bom índice de mulheres com ensino superior, porém, paradoxalmente também apresenta uma parcela significativa de mulheres analfabetas.

O abandono escolar precoce revela-se por motivos oriundos da necessidade de adentrar ao mercado de trabalho ou assumir atividades de cunho doméstico não remunerado. Nota-se que o estado possui uma porcentagem de $4,7 \%$ abaixo da média nacional, no entanto, dada a caracterização econômica e de desenvolvimento essa diferença poderia ser mais baixa (Tabela 6).

Tabela 6 - Taxa de abandono escolar precoce (\%) Divisões Territoriais 2010 Mulheres, 2010

\begin{tabular}{c|c|c}
\hline $\begin{array}{c}\text { Divisões } \\
\text { Territoriais }\end{array}$ & $\mathbf{2 0 1 0}$ & $\begin{array}{c}\text { Mulheres, } \\
\mathbf{2 0 1 0}\end{array}$ \\
\hline Santa Catarina & 33,8 & 29,1 \\
\hline Fonte: (INSTITUTO BRASILEIRO DE GEOGRAFIA E \\
$\begin{array}{c}\text { ESTATÍSTICA, 2011). } \\
\text { Principalmente as mulheres que residem }\end{array}$
\end{tabular}
no meio rural acabam por abandornar os bancos escolares em função do trabalho vinculado a subsistência da família.

\section{CONCLUSÃO}

A condição feminina em um estado que foi colonizado por imigrantes europeus por si só é um imenso desafio. A percepção machista das oligarquias e a representatividade das empresas familiares face à economia catarinense é preponderante.

É chegada a hora das mulheres deixarem de ocupar seu espaço, para definitivamente transformarem esse espaço em um ambiente equitativo e igualitário. Não é possível que uma economia fortalecida e diversificada não possa avançar nas políticas públicas destinadas ao empoderamento feminino.

Espera-se a partir dessa análise contribuir nos seguintes aspetos principais: promover uma reflexão dos modos de capital e do controle do trabalho; fortalecer o papel feminino no desenvolvimento da região; dar condições para as mulheres entenderem a importância do empoderamento feminino diante da exploração do trabalho por parte dos donos do capital; preparar as mulheres para um mercado de trabalho conectado com a sustentabilidade, tornando-as melhores e mais fortalecidas; demonstrar que no âmago dos resultados aportados sobre as estatísticas que tratam da questão de gênero existem questões tão profundas e obscuras que carecem de reanálise de maior atenção por parte das políticas públicas em todas as esferas.

Por fim, conclui-se que o enriquecimento feminino não se dará somente por valores econômicos e financeiros, pois a igualdade de gênero vai além das condições tangíveis, ela perpassa por meandros conectados com o sentimento de pertencimento e engajamento das mulheres no meio em que vivem e sobrevivem.

\section{REFERÊNCIAS}

ARENDT, H. A condição humana. 11. ed. Rio de Janeiro: Forense Universitária, 2010.

BENKO, G. Leitura Socioeconômica do fim do século. In: _. Economia, espaço e globalização: na aurora do século XXI. 3. ed. Tradução de Antônio de Pádua Danesi. São Paulo: Hucitec, 2002.

BRASIL. Ministério de Trabalho e Emprego. Santa Catarina gera mais de $\mathbf{5 0 . 0 0 0}$ postos em 2014. Brasília, DF, 2014. Disponível em:<http://portal.mte. gov.br/imprensa/sc-gera-mais-de-50-mil-postosem-2014.htm>. Acesso em: 25 jan. 2015.

FEDERAÇÃO DAS INDÚSTRIAS DO ESTADO DE SANTA CATARINA. Santa Catarina em dados: 2014 - Unidade Política de Economia Industrial. Florianópolis, 2014. v. 24.

GOULARTI FILHO, A. A formação econômica de Santa Catarina. In: CONGRESSO BRASILEIRO DE HISTÓRIA ECONÔMICA, 5.; CONFERÊNCIA INTERNACIONAL DE HISTÓRIA DE EMPRESAS, 6., 2003, Caxambu. Anais eletrônicos... Caxambu: 
ABPHE, 2003. Disponível em:<http://www.abphe. org.br/congresso 2003/Textos/Abphe_2003_52pdf>. Acesso em: 7 mar. 2015.

GUIMARÃES NETO, L. Desigualdades e políticas públicas regionais no Brasil: caminhos e descaminhos. Planejamento e políticas públicas, Brasília, DF, n. 15, p. 41-93, jun. 1997.

HARVEY, D. Condição pós-moderna: uma pesquisa sobre as origens da mudança cultural. Tradução de Adail Ubirajara Sobral e Maria Stela Gonçalves. 7. ed. São Paulo: Loyola, 2003. p. 135-184.

HIRATA, H. Globalização e divisão sexual do trabalho. Cadernos Pagu, Campinas, SP, n. 17-18, p. 139-156, 2001.

; KERGOAT, D. Novas configurações da divisão sexual do trabalho. Cadernos de Pesquisa, São Paulo, v. 37, n. 132, p. 595-609, set./dez. 2007.

INSTITUTO BRASILEIRO DE GEOGRAFIA E ESTATÍSTICA. Censo Demográfico 2010. Rio de Janeiro, 2011. Disponível em:<http://www.ibge.gov. br/home/estatistica/populacao/censo2010/> . Acesso em: 31 dez. 2014.

Pesquisa Nacional por Amostra de Domicílios: síntese de indicadores 2013. Rio de Janeiro, 2014. Disponível em:<http:// www.ibge.gov.br/home/estatistica/indicadores/ trabalhoerendimento/pnad_continua/>. Acesso em: 31 dez. 2014.

INVERNIZZI, N. El control y la calificación en el proceso de trabajo capitalista. In:

Flexibles y disciplinados: los trabajadores brasileños frente a la reestruturación productiva. México: Ed. Universidad Autónoma de Zacatecas, 2004. p 17-54.

LIPIETZ, A. As relações Capital-trabalho no limiar do século XXI. Ensaios FEE, Porto Alegre, v. 12, n. 1, p. 101-130, 1991

RUSCHEINSKY, A. (Org.). Sustentabilidade: uma paixão e movimento. Porto Alegre: Sulina, 2004

SAFFIOTI, H. I. B. Contribuições feministas para o estudo da violência de gênero. Cadernos Pagu, Campinas, SP, n. 16, p. 115-136, 2001.

THEIS, I. M. et al. CT\&I e desenvolvimento regional: os desafios da região Sul no contexto da economia globalizada do aprendizado. Revista Desenvolvimento em questão, ljuí, n. 6, p. 9-26, jul./dez. 2005.

YANNOULAS, S. C. Trabalhadoras: análise da feminização de profissões e ocupações. Brasília, DF: Abaré, 2013.
NOTA

Sob a perspectiva das Unidades da federação pontua abaixo apenas do Distrito Federal. Conforme dados da pesquisa PNAD em 2012 a diferença salarial a menor para as mulheres foi de $\mathrm{R} \$ 834,00$ e em 2013 foi de $\mathrm{R} \$ 871,00$. Percebe-se que diferença vem aumentando (INSTITUTO BRASILEIRO DE GEOGRAFIA E ESTATÍSTICA, 2014).

\section{Debora Aparecida Almeida}

Administradora

Mestre em Desenvolvimento Regional pela Universidade do Contestado (UnC) e Mestre em Desenvolvimento Regional pela Fundação Universidade Regional de Blumenau (FURB)

Professora vinculada a UnC

E-mail: deboraalmeida@unc.br

Universidade do Contestado - UnC

Av. Presidente Nereu Ramos, 1071 - Mafra/SC CEP: 89300-000 